\title{
BRAINSTEM AUDITORY EVOKED POTENTIAL RESPONSES IN PRIMARY HYPERSENSITIVE PATIENTS AND ITS CORRELATION WITH MEAN ARTERIAL BLOOD PRESSURE
}

\author{
Daya Ram Haldwani ${ }^{1 *}$, Asha Yadav², P. K. Rathore ${ }^{3}$, O.P. Tandon ${ }^{2}$ \\ ${ }^{1}$ Department of Physiology, Maulana Azad Medical College, Delhi-110002, India \\ ${ }^{2}$ Department of Physiology, University College of Medical Sciences, Dilshad Garden, Delhi-110095, India \\ ${ }^{3}$ Department of ENT, Lok Nayak Hospital, Delhi-110002, India
}

\section{ABSTRACT}

Background \& Objectives: The central nervous system (CNS) is frequently affected by primary hypertension leading to features of motor, sensory and cognitive deficits. Brainstem auditory evoked potentials (BAEPs) may provide an early evidence of sensory dysfunction. Correlation of BAEPs with severity of blood pressure has not been studied much. In the present study, BAEPs were recorded in primary hypertensive patients and its correlation with mean arterial blood pressure (MAP) was carried out.

Materials and Methods: BAEPs were recorded from $C z-A_{1} \& C z-A_{2}$ scalp regions in 30 hypertensive subjects and in 30 normotensive controls. Absolute peak latencies and interpeak latencies of different waves were compared in both the groups by using unpaired student's T test. Systolic, diastolic and mean arterial blood pressures were also compared between the groups. Bivariate correlation analysis was done to find out any correlation between mean blood pressure and different waves of BAEPs.

Results: Significant increase in peak latencies of wave I, IV \& V was seen in hypertensive subjects as compared to controls. Significant correlation between mean arterial pressure and absolute peak latencies of BAEP waves I, IV, V and interpeak latencies I-V, III-V was found in hypertensive patients. The amplitude of wave I was found to be negatively correlated with MAP.

Conclusion: This study indicates that auditory brainstem conduction pathways get delayed in hypertensive subjects and latencies are positively correlated with mean arterial blood pressure (MABP). Blood pressure regulatory mechanisms in the brainstem may influence the generators of different waves of BAEPs.

Keywords: Brainstem auditory evoked potential (BAEP), mean arterial pressure (MAP), primary hypertension, correlation

\section{INTRODUCTION}

Central nervous system dysfunctions are common in patients with primary hypertension and may lead to sensory, motor and cognitive deficit along with the symptoms of dizziness, vertigo, tinnitus, syncope and occipital headache. Moreover, hypertension appears to accelerate the course of atherosclerosis and increase the incidence of myocardial infarction as well as cerebral infarction. ${ }^{[1]}$ In addition, hypertension predisposes the small penetrating cerebral arteries to atheromatous changes leading to lacunar infarct in gray and white matter nuclei. These significant pathological changes were found in at least $50 \%$ of hypertensives. Any

*Corresponding author:

Email: drhaldwani@yahoo.co.in

http://dx.doi.org/10.20530/IJTA $32 \quad 28-34$

ISSN 2320-138X (c) 2016 behavioral effect of hypertension may be mediated by these structural changes in the brain, e.g. disseminated microaneurysms or lacunar infarcts. ${ }^{[2]}$ It is also conceivable that it could also be due to nonstructural changes such as an increase or decrease cerebral blood flow. ${ }^{[3]}$ Such type of microvascular damage may alter brainstem auditory evoked potentials (BAEP) which in turn may provide the early evidence for the presence of central nervous system dysfunction. BAEPs may be considered an experimental and investigational tool for screening hearing loss in hypertensive patients. ${ }^{[4]}$

Several studies have analyzed whether individuals with arterial hypertension have more hearing loss or not when compared to normal individuals by using pure tone audiometry or BAEPs. Some have found a relationship between hypertension and hearing loss while some have not. $[5],[6],[7]$ Results have been unclear, and there is the need for further studies as far as peripheral and 
central hearing are concerned in the affected population One of the studies has reported a correlation of peak latencies and interpeak latencies of waves of BAEPs with systolic and diastolic blood pressure ${ }^{[5]}$ but data is still lacking, and its correlation with mean blood pressure has not been studied.

Since the mean arterial blood pressure and pulse pressure are two important parameters which regulate the setting of the baroreceptor tone through lower brainstem cardiovascular centers, we conducted this study to find out the correlation between mean arterial blood pressure (MABP) and waves of BAEPs. Generators of waves of BAEPs in the brainstem may interact with the brainstem regulatory mechanisms of blood pressure in essential hypertension. Any such correlation would suggest an interaction of vasomotor tone regulatory mechanism with auditory pathways in the brainstem.

\section{MATERIAL \& METHODS}

Subjects: The study was conducted in the electrophysiology lab of Physiology Department of University College of Medical Sciences. 30 primary hypertensive subjects of age group 30-60 years were selected from the outpatient department of Guru Teg Bahadur Hospital as subjects for the present study. 30 healthy age \& sex matched normotensive adults served as controls. Almost $43 \%$ were male and $57 \%$ were female subjects in both the groups.

Selection of subjects: The criteria proposed by the seventh report of the Joint National Committee (JNC 7) for hypertension was adopted for the selection of subjects. Patients having systolic BP $\geq 140 \mathrm{mmHg}$ and diastolic $\geq 90 \mathrm{mmHg}$ on three consecutive days were included in this study as subjects. ${ }^{[8]}$ For controls, diastolic BP below $90 \mathrm{mmHg}$ and systolic BP below $140 \mathrm{mmHg}$ were considered. The ethical clearance from the ethical committee of the institution was obtained before starting the study. Informed consent was obtained from all the subjects and all of them filled up a Performa indicating personal and illness details of hypertension \& its associated clinical features. Subjects having any prior history of hypertension, diabetes, cardiovascular disorder, head injury, hearing problems, any long term medication and use of any ototoxic drug were excluded from the study.

Before putting subjects on antihypertensive drugs, these subjects were given a thorough checkup of the external ear canal with an otoscope by an ENT specialist to assure that the canal is not blocked by cerumen. Height, weight, BMI and other demographic details were also obtained in both the groups. Before recording the BAEPs, the procedure was properly explained to the subjects as well as to the controls. The auditory threshold was also recorded and subjects having an auditory threshold of $\leq 20 \mathrm{dBHL}$ were selected as subjects and controls to avoid any confounding factor affecting the hearing.

Test procedure: During the recording session, the subject lied comfortably in a supine position on a reclined bed. The scalp sites were cleaned with spirit swab and with Neuprep skin prepping jelly to abrade the skin \& to reduce the impedance. $\mathrm{Ag} / \mathrm{AgCl}$ scalp electrodes were then affixed with collodion at $\mathrm{Cz}-\mathrm{A} 1$ and $\mathrm{Cz}-\mathrm{A} 2$ positions of 10-20 international electrode placement system and ground electrode was placed on the forehead. Electrode to skin impedance was kept below 5 Kohms.

BAEPs were recorded after giving 2048 click stimuli of intensity $70 \mathrm{~dB}$ above the normal hearing threshold at a rate of $10 / \mathrm{sec}$ and $0.1 \mathrm{~m}$ sec duration monaurally. The other ear was masked by white noise $-40 \mathrm{~dB} \mathrm{HL}$. These clicks were generated by

Table 1: Demographic details of study and control groups

\begin{tabular}{lcc}
\hline & Study Group (Hyperten-sives) & $\begin{array}{c}\text { Control Group } \\
\text { (Normal Subjects) }\end{array}$ \\
\hline No. of subjects & 30 & 30 \\
Mean Age (years) & $46.48 \pm 7.23$ & $45.35 \pm 12.21(\mathrm{NS})$ \\
Body Mass Index $(\mathrm{kg} / \mathrm{m} 2)$ & $24.8 \pm 2.8$ & $22.1 \pm 3.2(\mathrm{NS})$ \\
Heart rate (in1 min) & $87.8 \pm 8.54$ & $80.2 \pm 6.22^{*}$ \\
Systolic blood pressure $(\mathrm{mmHg})$ & $147.8 \pm 3.99$ & $120.2 \pm 4.22^{*}$ \\
Diastolic blood pressure $(\mathrm{mmHg})$ & $94.4 \pm 4.68$ & $80.8 \pm 2.98^{*}$ \\
Mean blood pressure $(\mathrm{mmHg})$ & $111.23 \pm 9.85$ & $93.84 \pm 8.98^{*}$ \\
\hline
\end{tabular}


Table 2: Absolute peak latencies of wave I to $\mathrm{V}$ of brainstem auditory evoked potentials (BAEPs) in control \& hypertensive group.

\begin{tabular}{|c|c|c|c|c|c|}
\hline \multirow[t]{2}{*}{ Groups } & \multicolumn{5}{|c|}{ Absolute peak Latencies (Mean ? SD) in m Sec } \\
\hline & 1 & II & III & IV & $\mathrm{V}$ \\
\hline Control & 1.54 ? .15 & 2.59 ? .14 & 3.65 ? .19 & 4.72 ? .28 & 5.49 圆.23 \\
\hline Hypertensive & 1.63 田 .11 & 2.62 ? .21 & 3.72 ? .29 & 5.18 田 .22 & 5.99 目 .27 \\
\hline Significance & $0.033^{*}$ & 0.422 & 0.564 & $0.012^{*}$ & $0.002 *$ \\
\hline
\end{tabular}

Table 3: Inter Peak Latencies (IPLs) of BAEPs and amplitudes of wave I and V in controls \& primary hypertensives

\begin{tabular}{|c|c|c|c|c|c|}
\hline \multirow[t]{2}{*}{ Groups } & \multicolumn{3}{|c|}{ IPLs (mean ? SD) in m. sec. } & \multicolumn{2}{|c|}{ Amplitude $(\mu \mathrm{V})$} \\
\hline & $\mathrm{I}-\mathrm{V}$ & I-III & III-V & $\mathrm{I}$ & $\mathrm{V}$ \\
\hline Control & 3.98 目 .35 & 2.11 圆 .20 & 1.87 ? .48 & 0.29 目 .13 & 0.32 ? .16 \\
\hline Hypertensive & 4.30 ? . .32 & 2.16 ? .20 & 2.18 ? . .22 & 0.23 回.16 & 0.25 ? 10 \\
\hline Significance & $0.002 *$ & 0.701 & $0.001^{*}$ & $0.034 *$ & $0.048 *$ \\
\hline
\end{tabular}

passing $0.1 \mathrm{~m}$ sec square pulses through shielded headphones with alternating polarity. The signals picked by these electrodes were filtered ( $-6 \mathrm{~dB}$ point $100 \mathrm{~Hz} \& 3 \mathrm{KHz}$ ) amplified, averaged and displayed on the screen of MEB 5200, Evoked Potential Recorder (Nihon Kohden, Japan). Two trials of 2048 clicks were given to get a reproducible tracing of BAEPs. The female subjects in both the groups had slightly lower values of BAEPs as compared to males, but as these were not statistically significant, composite data in each group was taken into consideration. The absolute peak latencies of waves $\mathrm{I}$ to $\mathrm{V}$ and interpeak latencies I-V, I-III, III-V and amplitude of wave I \& V were calculated and averaged for both the ears.

Statistical Analysis: Unpaired student's " $T$ " test was used to compare the different parameters of BAEPs between primary hypertensive and control groups. Bivariate correlation analysis was done to find any correlation between mean arterial pressure and BAEP waves in hypertensive subjects as well as in controls.

\section{RESULTS}

The mean age of subjects was 46.48 ? 7.23years, and MABP was 111.23 ? $9.85 \mathrm{~mm} \mathrm{Hg}$ while themean age of controls was 45.35 ? 12.21 years and MABP was 93.84 ? $8.98 \mathrm{~mm} \mathrm{Hg}$. Other demographic details of subjects and controls are given in table 1 . The averaged values of BAEPs of left and right ears were taken into consideration.

Absolute peak latencies of wave I, IV and V in primary hypertensives are found to be significantly prolonged when compared to normal healthy normotensives. Absolute peak latencies of different waves in controls and subjects are given in table 2 . Interpeak latency I-V and III- V in hypertensives also found to be significantly prolonged as compared to their normal contemporizes. There is a significant reduction in the amplitudes of wave $\mathrm{I}$ and $\mathrm{V}$ in hypertensive patients. Inter-peak latencies I-V, I-III, III-V and amplitude of wave I and $\mathrm{V}$ are given in Table 3

Bivariate correlation analysis clearly shows a significant positive correlation between MABP and absolute peak latencies of wave I $(r=0.46, p=.01)$, wave IV $(r=0.44, p=.016)$ and wave $V(r=0.57, p=$ .001). (figures 1-3) Inter-peak latencies of wave I-V, III-V also showed significant correlation with MABP ( $r$ $=0.41 \& 0.42$ respectively) with $p<0.02$. (Figure 4 \&5) Amplitude of wave I showed a negative correlation with mean blood pressure in hypertensive subjects $(r=-0.42, p=.02)$.(figure 6) The ratio of wave $\mathrm{V} / \mathrm{I}$ was found to be $110 \%$ which was within normal range. 


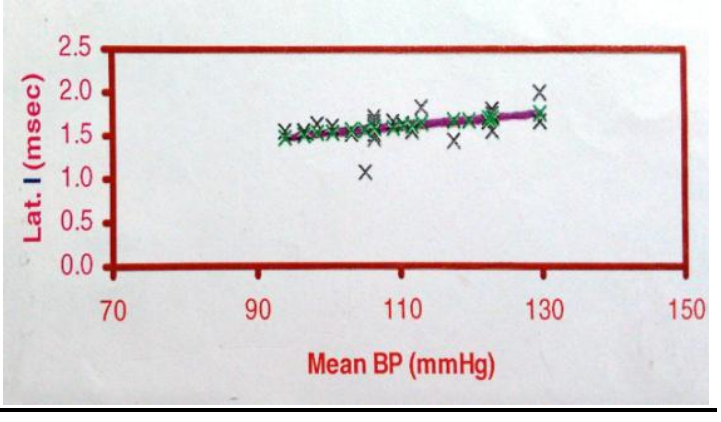

Figure1: Correlation of peak latency of wave-I of BAEP with MBP in primary hypertensives

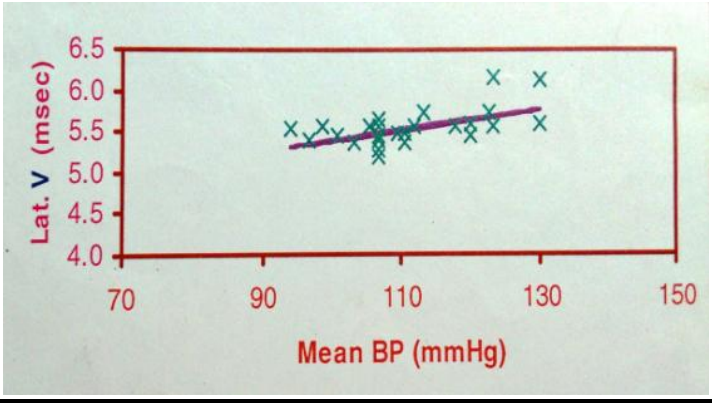

Figure 3: Correlation of peak latency of wave-V of BAEP with MBP in primary hypertensives

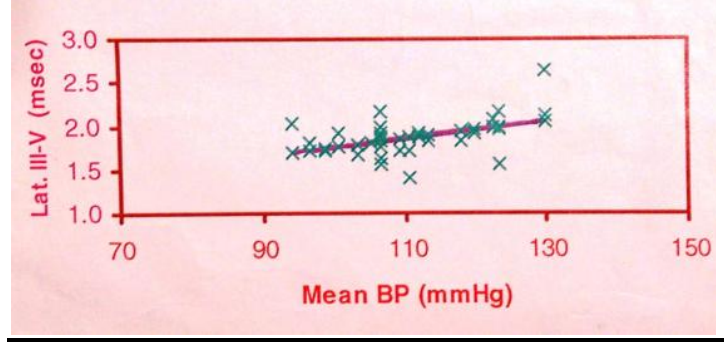

Figure 5: Correlation of inter-peak latency of III-V of BAEP with MBP in primary hypertensives

\section{DISCUSSION}

The present study showed that absolute peak latencies of wave I, IV and V of BAEPs significantly increases in primary hypertensives. These waves were also found to be positively correlated with mean blood pressure. Interpeak latencies I-V and III$\mathrm{V}$ was also found to be significantly prolonged and positively correlated with mean BP in hypertensive patients. This suggests that auditory conduction is delayed in these patients particularly at the level of inner ear and auditory pathways up to the medulla. Wave I usually represents the auditory conduction

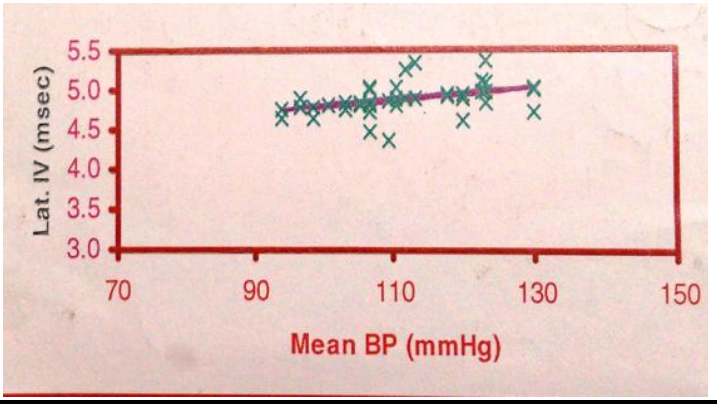

Figure 2: Correlation of peak latency of wave-IV of BAEP with MBP in primary hypertensives

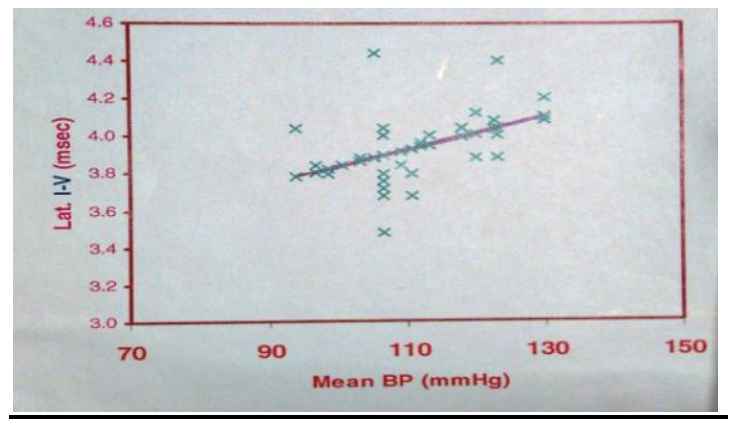

Figure 4: Correlation of inter-peak latency of I-V of BAEP with MBP in primary hypertensives

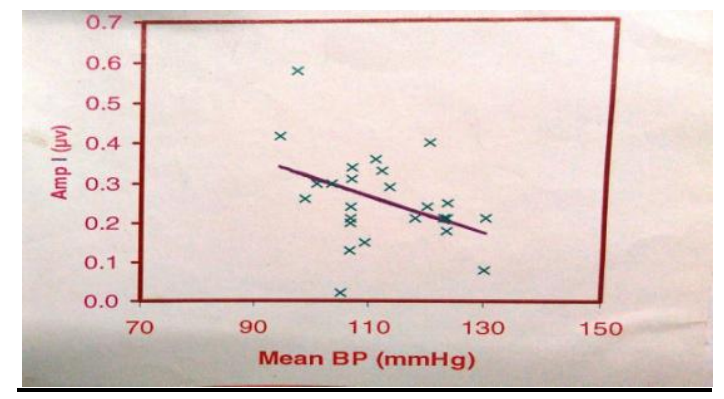

Figure 6: Correlation of amplitude of wave-I of BAEP with MBP in primary hypertensives

through the inner cochlea while waves IV and V are supposed to be generated from the trapezoid nuclei, lateral lemniscus and inferior colliculus nuclei in the brainstem. ${ }^{[9]}$ BAEPs evaluate the integrity of peripheral with the central auditory nerve pathways in the brainstem. Mean arterial blood pressure regulatory mechanisms in the brainstem might have influenced the functional integrity of these auditory pathways. These findings also indicate that brainstem auditory evoked potentials may become abnormal with the severity of hypertension or if treatment is delayed. 
The other significant finding was the reduction in the amplitudes of wave $\mathrm{I}$ and $\mathrm{V}$ in primary hypertensive patients and wave I was negatively correlated with MBP. But the ratio of amplitudes of wave $\mathrm{V} / \mathrm{I}$ which is a reliable indicator for any hearing impairment was found to be within normal range, i.e., $50 \%-300 \%$. This suggests that the neuronal excitation and conduction in the brainstem auditory pathway particularly inner cochlea and pontomesencephalic region might be delayed without any major hearing impairment. As the peak latencies and interpeak latencies are getting prolonged, so the present study can elaborate preemptive diagnosis to foresee impending complications. This may also provide an electrophysiological evidence of interaction of BP control mechanism in the brainstem with sensory conduction in auditory pathways in patients with essential hypertension.

The results of the present study are consistent with some of the studies where BAEP waves were found to be increased or delayed in hypertensive patients. $^{[5,6,7]}$ Prolonged interpeak latencies have also been noticed in benign intracranial hypertensive patients and authors proposed stetchingcompression of cochlear nerve as a mechanism for this. ${ }^{[10]}$ As far as correlation of waves of BAEPs with BP is concerned conflicting data is available. Rosen et al. stated that in a study carried out with hypertensive patients in the USA, there was a correlation between high blood pressure and hearing loss in high frequencies. ${ }^{[1]}$ However, such correlation was not seen in a later study carried out with a Sudanese native population. Hansen et al, in a retrospective study carried out in Denmark with 342 patients do not relate arterial hypertension to hearing loss in this population. ${ }^{[12]}$ Previous study from our department by a coauthor on smaller no. of patients reported a positive correlation of waves I, II of BAEPs with SBP and waves I and $V$ with DBP in primary hypertensive patients ${ }^{[5]}$ But there is still scarcity of correlation data of waves of BAEPs with blood pressure in primary hypertensives specially with mean blood pressure and we have not come across any study correlating the BAEP waves with MBP .

In the present study, we have selected patients as well as controls with an almost normal threshold so that other factors affecting the peripheral hearing loss can be ruled out and we can see the effect of primary hypertension specifically on the BAEPs. Most of the studies have also documented high frequency hearing loss in $>48$ years of age so we tried to select patients of $<48$ years so that we can avoid this confounding factor. ${ }^{[13]}$

Mean arterial blood pressure is the pressure for the distribution of steady flow and oxygen to the tissues and organs. It is an important parameter regulating baroreceptor tone setting in lower brainstem cardiovascular centres. The moment-tomoment regulation of the function of the heart and blood vessels is achieved through reflex action that detects and corrects changes in arterial pressure. It is now widely acknowledged that the baroreceptor heart rate (HR) reflex activity is diminished in animals with experimentally induced hypertension and in patients with essential hypertension. It has been shown in other experimental models of hypertension and in human hypertension that the attenuation of baroreceptor reflex sensitivity is mostly due to a reduced vagal activity. ${ }^{[14,][15]}$ This baroreceptor reflex reset at higher blood pressure for a given heart rate which may be related to physical changes in vascular wall dysfunction. ${ }^{[16],[17]}$

In experimental studies, a relationship was found between increased flow in the carotids and baroreceptor desensitization which suggests that atheroma may affect the compliance of vascular wall which thereby affects baroreceptors. ${ }^{[18]}$ Another link between atheroma and hypertension may be impairment of cardiovascular centers in medullary areas of CNS. This could be caused by the reduction of perfusion due to atheroma in the vertebrobasilar circulation. ${ }^{[19]}$ Baroreceptor dysfunction may be a contributory factor to hypertension. However, the contribution of impairment of these control mechanism to long-term essential hypertension is still not clear.

Moreover high pressure in the vascular system may damage the cochlear artery and anterior vestibular artery in the inner ear leading to a progressive hearing loss in hypertensive patients. ${ }^{[20],[21]}$ In hypertension blood viscosity also increases which reduces capillary blood flow, so oxygen transport to the cells of inner ear decreases. Sodium is also retained and extracellular volume increases in hypertension These changes may lead to the development of hypoxia and hearing loss in these patients. ${ }^{[22]}$.

Cardiovascular dysfunction and prolongation of BAEPs were usually accompanied by a reduction of cerebral blood flow, leading subjects to loss of consciousness and even death of the patient. ${ }^{[23]}$ 
Sensory derangement, particularly of pain threshold in experimental animals and impairments in sensory conduction in human beings has also been reported in hypertension. ${ }^{[24],[25],[26]}$

The finding of this study, i.e., significant correlation between mean arterial pressure and BAEP latencies \& IPL in primary hypertensive cases provides an electrophysiological evidence of interaction of BP control mechanism in the brainstem with sensory conduction in auditory pathways. MBP may affect the brainstem auditory pathways through various interactions which may influence conduction in the auditory pathways. More studies with more number of patients are required to understand more about the correlation of BP with BAEPs. This study provides an early electrophysiological evidence of BAEP and MBP derangement in primary hypertensive patients.

LIMITATIONS OF THE STUDY: This study had certain limitations. As newly diagnosed hypertensive patients were selected in this study but the duration of hypertension may remain a confounding factor. The sample size was small, and imaging was not done to exclude any infarct, lacunae or leukoaraiosis which can affect BAEPs. Moreover, the effect of antihypertensive treatment on the prolonged latencies of BAEPs was not studied. More studies are required to overcome the shortcomings of this study.

\section{REFERENCES}

1. Williams GH. In: Isselbacher KJ, Braunwald E, Wilson JD, martin JB, Fauci AS, Kasper DL Eds, Harrisons principles of internal medicine 13th ed. New York, McGraw-Hill Inc 1994; 1116-31

2. Frederic MW In: Con HL, Horwitz O Eds, Cardiac and vascular diseases. Philadelphia, Lea and Febiger 1971; 1473-1499

3. Jennings JR, Muldoon MF, Ryan CM, Mintun MA, Meltzer CC, Townsend DW, et al. Cerebral Blood Flow in Hypertensive Patients: An Initial Report of Reduced and Compensatory Blood Flow Responses During Performance of Two Cognitive Tasks. Hypertension. 1998 Jun 1;31(6):1216-22. Available from: http://dx.doi.org/10.1161/01.hyp.31.6.1216

4. Stockcard J.J. Stockard JE, Sharbrough FW. Brainstem auditory evoked potentials in Neurology: Methodology, interpretation and clinical application. In Electro diagnosis in clinical Neurology, $2^{\text {nd }} E D$. Aminoff AJ (Ed) Churchill Livingstone New York 1986, 467-503.

5. Tandon OP, Ram D, Awasthi R. Brainstem auditory evoked responses in primary hypertension. Indian J Med Res.1996; 104: 311-315.

6. Khullar S, Gupta N, Babbar R. Auditory Brainstem Responses \& Nerve Conduction Velocity in Essential Hypertension. VDP. 2009 Apr 2;6(1):51-5. Available from:

http://dx.doi.org/10.2174/1567270000906010051

7. Goyal G, Mittal A, Chaudhary C, Bachhel R, Grewal S, Rai $M$. The impact of severity of hypertension on auditory brainstem responses. Int J Med Public Health. 2014;4(3):218. Available from: http://dx.doi.org/10.4103/2230-8598.137704

8. The seventh report of the Joint National Committee on Detection, Evaluation Treatment of high blood pressure (JNC-VII). Hypertension 2003; 42: 1206

9. Møller AR, Burgess J. Neural generators of the brainstem auditory evoked potentials (BAEPs) in the rhesus monkey. Electroencephalography and Clinical Neurophysiology/Evoked Potentials Section. 1986 Sep;65(5):361-72. Available from: http://dx.doi.org/10.1016/0168-5597(86)90015-8

10. Sismanis A, Callari RH, Slomka WS, Butts FM. Auditory-Evoked Responses in Benign Intracranial Hypertension Syndrome. The Laryngoscope. 1990 Nov;100(11):1152???1155. Available from: http://dx.doi.org/10.1288/00005537-19901100000003

11. Rosen S, Bergman M, Plester D, El-Mofty A, Satti MH. LXII Presbycusis Study of a Relatively Noise-Free Population in the Sudan. Annals of Otology, Rhinology \& Laryngology. 1962 Sep 1;71(3):727-43. Available from: http://dx.doi.org/10.1177/000348946207100313

12. Hansen CC. Perceptive Hearing Loss and Arterial Hypertension. Archives of Otolaryngology - Head and Neck Surgery. 1968 Feb 1;87(2):119-22. Available from:

http://dx.doi.org/10.1001/archotol.1968.0076006012 1005

13. Wiley TL, Chappell R, Carmichael L, Nondahl DM, Cruickshanks KJ. Changes in Hearing Thresholds over 10 Years in Older Adults. Journal of the American Academy of Audiology. 2008 Apr 1;19(4):281-92. Available from: http://dx.doi.org/10.3766/jaaa.19.4.2

14. Sohmer H, Freeman S, Gafni M, Goitein K. The depression of the auditory nerve-brain-stem evoked response in hypoxaemia - mechanism and site of effect. Electroencephalography and Clinical Neurophysiology. 1986 Oct;64(4):334-8. Available from: 4694(86)90157-4

15. Honzikova N, Fiser B. Baroreflex Sensitivity and Essential Hypertension in Adolescents. Physiol. Res. 
2009; 58: 605-612

16. Sleight $P$. Role of the baroreceptor reflexes in circulatory control, with particular reference to hypertension. Hypertension. 1991 Nov 1;18(5_Suppl):III31-III31. Available from: http://dx.doi.org/10.1161/01.hyp.18.5_suppl.iii31.

17. Korner PI. BARORECEPTOR RESETTING AND OTHER DETERMINANTS OF BAROREFLEX PROPERTIES IN HYPERTENSION. Clinical and Experimental Pharmacology and Physiology [Internet]. WileyBlackwell; 1989 Jun;16(s15):45-64. Available from: http://dx.doi.org/10.1111/j.14401681.1989.tb02995.x

18. Chapleau MW, Hajduczok G, Shasby DM, Abboud FM. Activated endothelial cells in culture suppress baroreceptors in the carotid sinus of dog. Hypertension. 1988 Jun 1;11(6_Pt_2):586-90. Available from: http://dx.doi.org/10.1161/01.hyp.11.6.586.

19. Chapleau MW, Heesch CM, Abboud FM. Prevention or attenuation of baroreceptor resetting by pulsatility during elevated pressure. Hypertension. 1987 Jun 1;9(6_Pt_2):III137-III137. Available from: http://dx.doi.org/10.1161/01.hyp.9.6_pt_2.iii137.

20. De Moraes Marchiori LL, de Almeida Rego Filho E, Matsuo T. Hypertension as a factor associated with hearing loss. Brazilian Journal of Otorhinolaryngology. 2006 Jul;72(4):533-40. Available from: http://dx.doi.org/10.1016/s1808-8694(15)31001-6

21. Esparza CM, Jáuregui-Renaud K, Morelos CMC, Muhl GEA, Mendez MN, Carillo NS, et al. Systemic high blood pressure and inner ear dysfunction: a preliminary study. Clinical Otolaryngology. 2007 Jun;32(3):173-8. Available from: http://dx.doi.org/10.1111/j.1365-2273.2007.01442.x

22. Ohinata Y, Makimoto K, Kawakami M, Haginomori S-I, Araki M, Takahashi H. Blood Viscosity and Plasma Viscosity in Patients with Sudden Deafness. Acta OtoLaryngologica. 1994 Jan;114(6):601-7. Available from: http://dx.doi.org/10.3109/00016489409126112

23. Karamitsos DG, Kounis NG, Zavras GM, Kitrou MP, Goudevenos JA, Papadaki PJ, et al. Brainstem Auditory Evoked Potentials in Patients With Ischemic Heart Disease. The Laryngoscope. 1996 Jan;106(1):54-7. Available from: http://dx.doi.org/10.1097/00005537-19960100000011

24. Panfilov VV, Reid JL. Brain and autonomic mechanisms in hypertension. Journal of Hypertension. 1994 Apr;12(4):337???344. Available from: $\quad$ http://dx.doi.org/10.1097/00004872199404000-00002

25. Zamir N, Segal M. Hypertension-induced analgesia: changes in pain sensitivity in experimental hypertensive rats. Brain Research. 1979 Jan;160(1):170-3. Available from: http://dx.doi.org/10.1016/0006-8993(79)90614-0.

26. Chalmers J, Pilowsky P. Brainstem and bulbospinal neurotransmitter systems in the control of blood pressure. Journal of Hypertension. 1991 Aug;9(8):675-94. Available from: http://dx.doi.org/10.1097/00004872-19910800000001. 